\title{
The structure of personality constructs among Police Officers from Special Force KFOR
}

\author{
Piotr Próchniak \\ Pomeranian University, Slupsk, Poland
}

Email address:

piotrprochniak@wp.pl

To cite this article:

Piotr Próchniak. The Structure of Personality Constructs among Police Officers from Special Force KFOR. American Journal of Applied Psychology. Vol. 3, No. 6, 2014, pp. 159-165. doi: 10.11648/j.ajap.20140306.17

\begin{abstract}
A group of Police Officers from Special Force KFOR (Kosovo Force) who were the participants of a training preparing them for the peace mission in Kosovo took part in this study. The group consisted of 163 police officers, male only $(\mathrm{M}=32.5 ; \mathrm{SD}=5.2)$. Among the participants were antiterrorists, pyrotechnics and detectives. Police officers completed six psychological scales. These were: the ZKPQ Scale, the Value Survey, the Time Perspective Scale, the Ways of Coping Scale, the Sense of Coherence Scale and the Attitudes towards Death Scale. The results indicated: (1) numerous inter relationships obtained from correlation analyses of and (2) a four factor structure for the scales.
\end{abstract}

Keywords: Police Officers, Special Forces, Peace Missions, Personality

\section{Introduction}

The work of police officers is both physically and emotionally intense. A high level of emotional dedication is demanded in the performance of occupational tasks in difficult and unsafe situations such as chasing down criminals, crackdowns, participating in interventions, establishing contact with hostile and aggressive people, informing families about the deaths of relatives, helping desperate people and so forth. The police officers work can be characterized by the presence of danger, loss, risk, or potential injury. Work of police officers is often seen as an courageous, noble profession and worthy of public notice (Próchniak, 2012).

This article presents personality aspects of a very specific group of police officers - the police officers from special force (KFOR - Kosovo Force) preparing to the peace mission in Kosovo (Balkans - Europe). Special forces are supposed to function effectively in small autonomous groups, and be able to quickly adapt to varying circumstances, mission demands, and different socio-cultural contexts (Garbarino, et al., 2012). Selection procedures for special forces are very rigorous. These forces have usually secret character thus a very few studies addressed the personality of special forces officers.

Braun, et al., (1994) found that U.S. Navy Sea-Air-Land commando volunteers (SEALs) were more extraverted and less neurotic than the general population. McDonald, et al., (1990) found that graduated US Navy SF candidates were more extravert and more emotionally stable (low neuroticism) than non-graduates, Picano, et al., (2002) found that extraversion and agreeableness discriminated among graduates and non-graduates. In study, Dean, et al., (2006) found that extraversion, openness and conscientiousness significantly predicted performance training of Marines attending Marine Corps' recruiters. Surprisingly, low extraversion among Norwegian Naval SFs candidates, predicted higher chances of success (Hartman, et al., 2003). Garbarino and coworkers (2012) found different personality profiles among Italian police Special Force (SF) officers. Two distinct personality profiles were found: police officers in first profile were similar to the general population, with the exception of a higher self-reported emotional stability and self-deceptive enhancement, police officers in the second profile showed lower scores in measures of depression, anxiety, professional exhaustion, loss of empathy, and higher scores in a measure of organizational resilience.

In this article other potentially important personality constructs of police officers from special forces are presented: personality traits from perspective of Zuckerman model (1992), preferred values, time perspective, coping ways, sense of coherence and attitudes towards death.

Personality traits are primary motivational factors in risk-taking behaviors, it is of interest to discover the motivational factors among police officers. One motivation 
to be a police officer can be the expression of a personality trait, namely, sensation seeking (Zuckerman, 1994). This has been defined as "seeking varied, novel, complex and intense sensations and experiences and the willingness to take physical, social, legal, and financial risks for the sake of such experience" (Zuckerman, 1994, p. 27). A substantial amount of the research on sensation seeking has been associated with the work of police officers (Carlson \& Lester, 1980; Homant, Kennedy, \& Howton, 1993; Goma-i-Freixanet \& Wismeijer, 2002; Levin \& Brown, 1975).

Studies carried out on police officers may cover more than sensation seeking on the part of the individual (Burbeck \& Furnham, 1984; Goma-i-Freixanet \& Wismeijer, 2002). This study set out to use Zuckerman's model (1992) in order to look for the personality of police officers. Zuckerman distinguished five personality traits; Impulsive Sensation Seeking, Neuroticism, Activity, Sociability, and Aggression/Hostility (Zuckerman, Kuhlman, Joireman, Teta, \& Kraft, 1993).

From perspective of this model Próchniak (2009b) discovered that Polish policemen scored lower on Neuroticism and higher Impulsive Sensation seeking domains than the control group of prosocial workers.

As well as employing Zuckerman's model (1992) in order to identify the personality characteristics of police officers, this study included the use of Schwartz's Value Model for the purpose of distinguishing the value characteristics for police officers. Schwartz views values as something which can be treated as existential; they possess concrete meaning in concrete situations and contexts, as well as a cross-situational character (Schwartz, Sagiv, \& Boehenke, 2000). They make up the essential criterion which allows an individual's behavior to be estimated and a particular order to be characterized. Some values are very important for the subject, while others are less so. The Schwartz Value Survey allows the following types of values to be distinguished: Self-Direction; Stimulation; Hedonism; Achievement; Power; Security, Conformity; Tradition; Benevolence; and Universalism. These values are the basic principles which guide individual behavior throughout life (Schwartz, 1992).

Personal values have also been shown to be a motivating factor in police officers work (Próchniak, 2009a). In Lester's study (1983), values such as earning money and job stability were shown to be more important to the police officer subjects. Research conducted by Hopper (1977) produced similar results, demonstrating that the police officers in question were motivated by materialistic benefits. Griffeth and Cafferty (1977) found that their respondents rated values relating to private issues such as self-respect and family security highly and assigned a low priority to those connected with social issues, like social recognition, for instance. A family tradition of serving with the police proved to be important in choosing this profession on Taiwan (Tarng, Hsieh \& Deng, 2001). In contrast to the studies mentioned thus far, other research (Meagher \& Yentes, 1986; Raganella $\&$ White, 2004) has shown that it is not only job stability or salary which is important factor, but also the excitement involved in the work.

Values are located in the time perspective. The analysis of people's time perspective can be an important source of knowledge about human activity, including courageous acts. Research into the time perspective in the context of risk taking is rather rare. Studies have indicated that a strong concentration on the present is conducive to the hedonistic risky activity: risky driving or using drugs (Zimbardo, et al., 1997, 1999). Little research exist about time perspective of modern heroes. Próchniak (2014) found that firefighters had score higher on temporal organization of activity (using of time, planning, telicity, detail) than controls.

Work of policemen is often associated with extensive emotional and physical involvement. Police officers must coping with stressful events. Coping has a long tradition in the literature. It is defined as the specific efforts, both behavioral and psychological, which people make in order to reduce or minimize stressful events, including unfavorable weather (Lazarus \& Folkman, 1984). Two forms of coping are usually distinguished, namely, problem-solving strategies and emotion-focused strategies. The former concentrate on endeavors to do something active to eliminate the stressful circumstances. The latter involve attempts to regulate their emotional consequences. The predominance of one strategy over another is determined both by individual traits and the nature of the event in question (Kobasa, 1979; Lazarus \& Folkman, 1984). Studies indicate that individual differences exist between policemen in stressful situations (Paton \& Violanti, 1996; Violanti \&Aron, 1993).

A similar to the coping strategies is sense of coherence construct proposed by Antonovsky (1987). The sense of coherence tries to explain why people stay healthy or ill in risky situations. The core of this orientation is the focus on successful coping through the selection of realistic coping strategies.

This work examines sense of coherence of police officers from special force.

The death is border of our goals and our time of life. Problem of death becomes particularly important in analyzing of occupational groups, such as firefighters or policemen, who risk their own life for others. The results of these works are inconclusive. Some studies suggested low death anxiety of courageous than a controls (Griffith \& Hart 2005; Kaspar \& Vesper 1976), others revealed such differences (Alexander \& Lester 1972; Fang-juan Liao,1999; Próchniak 2011). In this study attitudes towards death among police officers form special force will be analyzed.

The main goal of this study is to explore structure of personality constructs among policemen from special force.

\section{Method}

\subsection{Particpants}

A group of police officers who were the participants of a special training preparing them for the peace mission in Kosovo took part in this study. The group consisted of 163 
policemen, male only $(\mathrm{M}=32.5 ; \mathrm{SD}=5.2)$. The mean years of work experience was 10 years. The special course took place at the Police School in Slupsk, Poland. Among the participants there were antiterrorists, pyrotechnics and detectives. Participation in the course was voluntary.

\subsection{Procedure}

Police officers were generally informed about the goals of the research. Each participant first had to answer several questions regarding age, sex, and the years of job experience. The study of police officers was conducted during the training at the Police School in Slupsk in the Police School's classrooms. Participants answered the questionnaire questions in groups of 10 to 40 people. After the introduction to the study goal and giving instructions about the questionnaire, the policemen individually filled in the questionnaire.

\subsection{Measures}

The six questionnaires administered to the policemen sample were the ZKPQ Scale, the Value Survey, the Time Perspective Scale, the Ways of Coping Scale, the Sense of Coherence Scale and the Attitudes towards Death Scale.

Zuckerman - Kuhlman Personality Questionnaire - ZKPQ (Zuckerman, et al., 1993).

The Zuckerman-Kuhlman Personality Questionnaire, a tool designed to measure the alternative five-factor model of personality, was translated and adapted into the Polish language. The ZKPQ questionnaire consists of 99 True-False statements. The Polish version has provided satisfactory Cronbach coefficients alpha: Impulsive Sensation Seeking (Cronbach's $\alpha=.72$ ); Neuroticism / Anxiety (Cronbach's $\alpha$ $=.90)$; Activity (Cronbach's $\alpha=.81$ ); Sociability (Cronbach`s $\alpha=.82$ ); Aggression / Hostility (Cronbach`s $\alpha$ $=.83)$.

Value Survey (Schwartz, 1992).

The second questionnaire to be used was the Value Survey containing 57 values. The Value Survey was translated and adapted into the Polish language. Each value was rated on a 9 point scale, ranging from "opposed to my principles" (-1) over "not important" (0) to "of supreme importance" (7). Reliabilities (Cronbach's alphas) of the value types were as follows: self-direction (Cronbach 's $\alpha=.63$ ), stimulation (Cronbach's $\alpha=.67$ ), hedonism (Cronbach's $\alpha=.66$ ), achievement (Cronbach `s $\alpha=.70$ ), power (Cronbach `s $\alpha=.73$ ), conformity (Cronbach's $\alpha=.57$ ), tradition (Cronbach's $\alpha$ $=.54$ ), security (Cronbach's $\alpha=.61$ ), benevolence (Cronbach's $\alpha=.68$ ), universalism (Cronbach's $\alpha=.76$ ), self-enhancement (Cronbach's $\alpha=.78$ ), openness to change (Cronbach's $\alpha=.74$ ), self-transcendence (Cronbach's $\alpha$ $=.73$ ), conservation (Cronbach 's $\alpha=.67$ ). In this study only metacategories of values will be used.

Time Perspective Questionnaire (Próchniak, 2011).

In the present study Time Perspective Questionnaire of own authorship was used. The questionnaire included two subscales, which investigated concentration on the present
(Cronbach's $\alpha=.82$ ) and concentration on the future (Cronbach's $\alpha=.74$ ). Particular sentences included in this questionnaire were evaluated by means of the 5-degree Likert scale (1-Strongly disagree; 5-Strongly agree). Reliability of test-retest after four weeks for the scale of concentration on the present equaled ,78 whereas for the scale of concentration on the future, 73 .

The Ways of Coping Questionnaire (WCQ) (Folkman \& Lazarus, 1988).

WCQ was used in polish adaptation of P. Oleś (1995). WCQ measures how people cope with the stresses of everyday life (Folkman \& Lazarus, 1988). Response is to a 4 point scale. WCQ measures two main coping strategies: problematic strategies (Cronbach's $\alpha=.86$ ) and emotional strategies (Cronbach's $\alpha=.87$ ). In Polish version WCQ consists of 80 items.

Sense of Coherence Scale (Koniarek, Dudek, \& Makowska, 1993).

Antonovsky's Sense of Coherence Scale is a 29-item, 7-point semantic differential scale translated into Polish. It is composed of an overall scale score and three subscale scores (Comprehensibility, Manageability and Meaningfulness). Each item is presented on a 7 - point Likert scale. The SOC scales include alpha reliabilities between .74 and .91 .

Death Attitude Questionnaire (Próchniak, 2011).

The Attitude Death Questionnaire was constructed by the author of this research. The questionnaire contains 24 items, with four items being utilized per factor. Participants are asked to indicate the extent to which they agree with each of items, using a subscale from 1 (strongly disagree) to 7 (strongly agree). The first factor is called "Beliefs in life after death". (Cronbach's $\alpha=.72$ ). For example, one item that assesses beliefs in life after death is "Life exists after death". Second factor is called "Contemplation of death". (Cronbach's $\alpha=.87$ ). One item that exemplifies the contemplation of death items is "I like to listen to consideration about death". "Fear of death " is the third factor (Cronbach's $\alpha=.72$ ) (e.g. I feel fear on thought about death). The fourth factor measured by the Attitude toward death Questionnaire is called "Preferred kind of death"(Cronbach's $\alpha=.77)$. For example, one of the items from the questionnaire assesses preferred kind of death is "I desire to have fast and unexpected death". The fifth factor is called "Beliefs about controlling death" (Cronbach's $\alpha=.76$ ). For example, one item that assesses beliefs about controlling death is I belief that I can avoid death in extreme dangerous situation. The final factor is called "Paranormal beliefs about death" (Cronbach's $\alpha=.80$ ). (e.g. Horoscopes are able to forecast date of death).

\section{Results}

In terms of statistical analysis, first, means and standard deviations for the ZKPQ Scale, the Value Survey, the Time Perspective Scale, the Ways of Coping Scale, the Sense of Coherence Scale and the Attitudes towards Death Scale are presented (Table 1). Second, Pearson product correlations 
were used to compare all scales, Third, factor analysis was carried out on policemen's scores.

Table 1. Means, standard deviations, and for ZKPQ, Value Survey, Time Perspective Scale, Ways of Coping Questionnaire, Sense of Coherence Scale and Death Attitude Questionnaire.

\begin{tabular}{lll}
\hline Subcomponents & M & SD \\
\hline Impulsive Sensation Seeking & 9.87 & 3.42 \\
Neuroticism & 6.80 & 3.63 \\
Sociability & 7.58 & 3.27 \\
Aggression/ Hostility & 5.25 & 2.84 \\
Activity & 8.87 & 3.00 \\
Self-enhancement & 4.02 & 1.05 \\
Self-transcendence & 4.70 & .91 \\
Openness to change & 4.42 & 1.00 \\
Conservation & 4.57 & .88 \\
Present Time Perspective & 3.21 & .46 \\
\hline
\end{tabular}

\begin{tabular}{lll}
\hline Subcomponents & M & SD \\
\hline Future Time Perspective & 3.21 & .33 \\
Problematic Strategies & 6.24 & 1.16 \\
Emotional Strategies & 11.47 & 3.09 \\
Sense of Coherence & 4.69 & .75 \\
Paranormal beliefs about death & 2.61 & 1.29 \\
Contemplation of death & 3.30 & 1.38 \\
Fear of death & 3.67 & 1.39 \\
Beliefs about controlling death & 4.14 & 1.23 \\
Preferring kind of death & 4.86 & 1.35 \\
Beliefs in life after death & 4.43 & 1.36 \\
\hline
\end{tabular}

In order to explore any inter scale correlations which might exist amongst the different scales and their subcomponents, Pearson product-moment correlational analysis was carried out (Table 2).

Table 2. Correlations among subcomponents of ZKPQ, Value Survey, Time Perspective Scale, Ways of Coping Questionnaire, Sense of Coherence Scale and Death Attitude Questionnaire.

\begin{tabular}{|c|c|c|c|c|c|c|c|c|c|c|c|c|c|c|c|c|c|c|c|c|}
\hline & 1 & 2 & 3 & 4 & 5 & 6 & 7 & 8 & 9 & 10 & 11 & 12 & 13 & 14 & 15 & 16 & 17 & 18 & 19 & 20 \\
\hline 1 & & & & & & & & $.33^{*}$ & & $.25^{*}$ & & & & & & & & $.19^{*}$ & $.25^{*}$ & \\
\hline 2 & & & & & & $.22^{*}$ & & & $.20^{*}$ & & & $-.40^{*}$ & $.43^{*}$ & $-.58^{*}$ & $.33^{*}$ & $.25^{*}$ & $.31^{*}$ & & $-.23^{*}$ & $.17^{*}$ \\
\hline 3 & & & & & & & & & & & & & & $.18^{*}$ & & & & & & $-.22^{*}$ \\
\hline 4 & & & & & & $.22^{*}$ & & & & & & $-.16^{*}$ & & $-.32 *$ & $.19^{*}$ & & $.19^{*}$ & & & \\
\hline 5 & & & & & & & & & & $.17^{*}$ & & $.20^{*}$ & & $.17^{*}$ & & & & & & \\
\hline 6 & & $.22^{*}$ & & $.22^{*}$ & & & & & & & & & & $-.16^{*}$ & & & $.15^{*}$ & & & \\
\hline 7 & & & & & & & & & & & $.16^{*}$ & & & & & & & & & $.22^{*}$ \\
\hline 8 & $.33^{*}$ & & & & & & & & & & & & & & & & & & & \\
\hline 9 & & $.20^{*}$ & & & & & & & & & & & & & & & & & & \\
\hline 10 & $.25^{*}$ & & & & $.17^{*}$ & & & & & & & & $.31^{*}$ & $-.17^{*}$ & $.25^{*}$ & & & & & \\
\hline 11 & & & & & & & $.16^{*}$ & & & & & $.23^{*}$ & & $.39^{*}$ & & $.15^{*}$ & & $.19^{*}$ & $.17^{*}$ & \\
\hline 12 & & $-.40^{*}$ & & $-.16^{*}$ & $.20^{*}$ & & & & & & $.23^{*}$ & & & $.45^{*}$ & & & $-.18^{*}$ & $.23^{*}$ & $.24^{*}$ & \\
\hline 13 & & $.43^{*}$ & & & & & & & & $.31^{*}$ & & & & $-.52^{*}$ & $.45^{*}$ & $.30^{*}$ & $.23^{*}$ & & $-.18^{*}$ & \\
\hline 14 & & $-.58^{*}$ & $.18^{*}$ & $-.32^{*}$ & $.17^{*}$ & $-.16^{*}$ & & & & $-.17^{*}$ & $.39^{*}$ & $.45^{*}$ & $-.52^{*}$ & & $-.29^{*}$ & & $-.24^{*}$ & $.15^{*}$ & $.19^{*}$ & \\
\hline 15 & & $.33^{*}$ & & $.19^{*}$ & & & & & & $.25^{*}$ & & & $.45^{*}$ & $-.29^{*}$ & & & & & & \\
\hline 16 & & $.25^{*}$ & & & & & & & & & $.15^{*}$ & & $.30^{*}$ & & & & & & & \\
\hline 17 & & $.31^{*}$ & & $.19^{*}$ & & $.15^{*}$ & & & & & & $-.18^{*}$ & $.23^{*}$ & $-.24^{*}$ & & & & & & \\
\hline 18 & $.19^{*}$ & & & & & & & & & & $.19^{*}$ & $.23^{*}$ & & $.15^{*}$ & & & & & & \\
\hline 19 & $.25^{*}$ & $-.23^{*}$ & & & & & & & & & $.17^{*}$ & $.24^{*}$ & $-.18^{*}$ & $.19^{*}$ & & & & & & \\
\hline 20 & & $.17^{*}$ & $-.22^{*}$ & & & & $.22^{*}$ & & & & & & & & & & & & & \\
\hline
\end{tabular}

${ }^{*} \mathrm{p}<.05$

1 - Impulsive Sensation Seeking; 2 - Neuroticism; 3 - Sociability; 4 - Aggression / Hostility; 5 - Activity; 6 - Self - enhancement; 7 - Self-transcendence; 8 Openness to change; 9 - Conservation; 10- Present time perspective; 11 - Future Time Perspective; 12 - Problematic strategies; 13 - Emotional strategies; 14 Sense of coherence; 15 - Paranormal beliefs about death; 16 - Contemplation of death; 17 - Fear of death; 18 - Beliefs about controlling death; 19 - Preferring kind of death; 20 - Beliefs in life after death.

A number of important correalational links for scale subcomponents were obtained (sensation seeking and openness to change, present time perspective, control of death, preferring fast kind of death; neuroticism and self enhancement, conservation, problematic strategies, emotional strategies, sense of coherence, paranormal beliefs about death, contemplation of death, fear of death, preferring slow of death and beliefs in life after death; sociability and sense of coherence, beliefs in life after death; aggression/hostility and self - enhancement, problematic coping, sense of coherence, paranormal beliefs about death, fear of death; activity and present time perspective, problematic strategies, sense of coherence; self - enhancement and sense of coherence, fear of death; self-transcendence and future time perspective, beliefs in life after death; present time perspective and emotional strategies, self coherence, paranormal beliefs about death; future time perspective and problematic strategies, sense of coherence, contemplation of death, beliefs about controlling of death, preferring of fast death; problem strategies and sense of coherence, fear of death, preferring fast of death and beliefs about controlling death; emotional strategies and sense of coherence, paranormal beliefs about death, fear of death, contemplation of death; sense of coherence and paranormal beliefs about death, fear of death and preferring fast of death, beliefs about controlling death.

Correlations between subscales suggest that exists deeper, unexplained structure of variables of policemen from special force, thus the next step conducted factor analysis scales 
(Varimax rotated factor with Kaiser Normalisation) to discover base and main personality factors of Polish police officers from special force. Results of factor analysis are presented in table 3 .

Table 3. Factor Analysis for the twenty scales (Varimax rotated factor with Kaiser Normalisation).

\begin{tabular}{|c|c|c|c|c|}
\hline Variables & $\begin{array}{l}\text { Factor } \\
-1\end{array}$ & $\begin{array}{l}\text { Factor } \\
-2\end{array}$ & $\begin{array}{l}\text { Factor } \\
-3\end{array}$ & $\begin{array}{l}\text { Factor } \\
-4 \\
\end{array}$ \\
\hline Impulsive Sensation Seeking & & & & .56 \\
\hline Neuroticism & -.63 & & .40 & \\
\hline Sociability & & & & .62 \\
\hline Aggression / Hostility & -.44 & & & \\
\hline Activity & & & & .54 \\
\hline Self - enhancement & & .80 & & \\
\hline Self-transcendence & & .87 & & \\
\hline Openness to change & & .81 & & \\
\hline Conservation & & .90 & & \\
\hline Present time perspective & & & & .58 \\
\hline Future time perspective & .59 & & & \\
\hline Problematic strategies & .65 & & & \\
\hline Emotional strategies & & & .56 & \\
\hline Sense of coherence & .83 & & & \\
\hline Paranormal beliefs about death & & & .72 & \\
\hline Contemplation of death & & & .81 & \\
\hline Fear of death & & & .47 & \\
\hline Beliefs about controlling death & .73 & & & \\
\hline Preferring kind of death & & & & .41 \\
\hline Beliefs in life after death & & & & -.44 \\
\hline Variance $(\%)$ & 18.18 & 14.92 & 10.71 & 9.34 \\
\hline Eigenvalue & 3.63 & 2.99 & 2.14 & 1.87 \\
\hline
\end{tabular}

The four factors accounted for almost $53 \%$ of the total variance. The first factor which accounted for $18 \%$ of the variance (eigenvalue $=3.63$ ) represents dimension "effective organization of risky activity" (subcomponents: neuroticism, aggression / hostility, future time perspective, problem coping, sense of coherence). The second factor which accounted for $15 \%$ of the variance (eigenvalue $=2.99$ ) is connected with values and is labeled "direction of risky activity" (subcomponents: self - enhancement, self-transcendence, openness to change, conservation). The third factor which accounted for $11 \%$ of the variance (eigenvalue $=2.14$ ) represents a dimension of "affective organization of risky activity" with loadings on neuroticism, emotional strategies, paranormal beliefs about death, fear of death, contemplation of death, control of death. The last factor, which accounted for $9.34 \%$ of the variance (eigenvalue $=1.87$ ), labelled "seeking physical risk" (subcomponents: impulsive sensation seeking, sociability, activity, present time perspective, preferring kind of death beliefs in life after death).

\section{General Discussion}

Main goal of the study was analysis of the deep structure of personality constructs among Polish police officers participated in peace mission in Kosovo in the Balkans. Factor analysis revealed four - factor structure of personality constructs among police officers.

The first factor to emerge was labeled "effective organization of risky activity". It seems that this factor describes the specific efforts, both behavioral and psychological, which police officers make in order to reduce or minimize stressful events in work place (Lazarus \& Folkman, 1984). This factor includes strategies involve trying to change the nature of the work stressor itself too (Carver \& Connor-Smith, 2010). The very important aspect of this factor is sense of coherence. It means that this factor includes a sense of control over stressing or dangerous events, a feeling of commitment to various work values and task, and a perception of work risk as a challenge (Anotonovsky, 1987). Finally, this factor also consists of the future time perspective subcomponent. It means that effective organization of risky activity is concentrated on the future consequences of present tasks.

The second factor was called "direction of risky activity" This factor consists of four metacategories of values and its describes what is important for police officers. It includes the basic principles that guide behavior of police officers. Of course, we must remember that values not explain specific behavior than rather behavioral patterns (Bond, Leung, \& Schwartz, 1992).

The third factor was called "affective organization of risky activity". This factor includes following subscales: emotional strategies, paranormal predictions of death, fear of death, contemplation of death. It seems, that this factor describes emotional functioning of police officers in dangerous, risky situations, emotional coping with stress, emotions or irrational thinking towards problem of death in work. This factor consists of reflections about phenomenon of death too.

The last factor "seeking physical risk" includes following subcomponents: impulsive sensation seeking, sociability, activity, present time perspective, preferring fast kind of death and beliefs in life after death. It seems that this factor describes looking for new, intensive and excitement physical experiences in work place of police officers.

Above results indicate on interesting question: Why does "effective organization of risky activity" is most important factor in explaining personality aspects of police officers? Most simply, this result could be explained through analysis of professional work of police officers. If a police officers want to pursue unsafe occupational goal must precisely plan behavior, must concentrate on the goals and must effectively cope with a stress. If police officers fail to give attention to these matters, the consequences may be tragic, and might even lead to their death.

Probably risks that police officers take in the course of their work are most often instrumental by nature because they must often take risks in order to achieve these goals, which are usually located in the future a dangerous occupational task. From this perspective subcomponent future time perspective in this factor - is clear and understand.

This factor includes sense of coherence subcomponent. It means that police officers must perceive that competences are at one's disposal which are adequate to meet demands posed by the stimuli that bombard policemen in risky 
situations. The police officers must have to show an emotional involvement and feel strongly about some unsafe situation in their work.

Characteristics for police officers from perspective of the first factor are: self-confidence, low emotional reactivity, strong even in rigorous circumstances. Police officers makes decisions quickly, without wavering, know what they want, are able to use their time effectively in order to achieve their occupational tasks. They not prefer immediate pleasures and it is easy for them to postpone getting an award. They believe in their own ability to cope with the most difficult sphere of hazards. To them, difficult work situation is a place for experiencing challenge. Police officers have a positive attitude toward new events which demand risk taking, perceiving them as a source of challenge. They perceive occupational dangers as less stressful because they have more resources at their disposal to cope with life problems (Kobasa, 1979). Finally, they try to influence the outcomes of the work events, both positive and negative (Antonovsky, 1987).

The second factor was called "direction of risky activity". Surprisingly not sensation seeking trait but preferred values are more important in explaining personality aspects of the police officers. It means that police officers not will, during their professional work, be searching unknown and uncertain, thus extreme situations not will the main goal of their work. Rather - security and social order - are more important for police officers (of course we must remember that openness to change is the part of this factor too).

Results of this study aren't in accordance to the previous study of sensation seeking trait (Jack \& Ronan, 1998; Zuckerman, 1994). In this context is important question about relation between personality traits and preferred values. Personality traits and values in partly are difference and similar. The main distinction between personality traits and values is that traits describe question "what people are like", values describe "what people consider important?". Another distinction is that traits are more biological determined than values. Values depends more on social influents and cognitive control, they changed trough socialization. Personality traits and values guide behavior (Roccas, Sagiv, Schwartz \& Knafo, 2002). From this perspective - question "what police officers consider important" can explain stronger the structure of personality of police officers than "what police officers are like". Of course, we must remember that preferred values of police officers are more susceptible to change through socialization and low stable.

The third factor describes emotional functioning of police officers, particularly in the context of death. The work of police officers is intense, both physically and emotionally, and the hazards it entails include the extreme risk (real possibility of death). In this context - meaning of this factor is more clear and understand.

Evolution has programmed us to perform activities that will enhance the probability of survival. From evolutional perspective fear of death serves a protective purpose, thus fear is a normal and health human reaction. Fear can inform of police officers about danger, more over - fear prepares police officers to deal with it - in the consequence - action of policemen is more responsible.

Last factor includes positive attitudes towards physical risk. Surprisingly, this factor explains little percent of variance in psychological functioning of police officers from special force. This result can be explaining in similar way as the factor number 2. Police officers not seek joyful affect in realization of dangerous tasks and sensation seeking isn't main goal of their job.

The received results of this study have important limitations that concern the explanation of structure of personality of policemen from special force. The results of the research were obtained on a relatively small group of police officers. In this study participated policemen with highest occupational competences therefore results of this study aren't represent for all of policemen.

Finally, the results have practical consequences during the process of recruitment and selection for the special forces (Garbarino, et al., 2012).

\section{References}

[1] Alexander, M., \& Lester D. (1972). Fear of death in parachute jumpers. Perceptual and Motor Skills, 34, 338.

[2] Antonovsky, A. (1987). Unraveling the Mystery of Health how people manage stress and stay well. San Francisco: Jossey-Bass Publishers.

[3] Bond, M. H., Leung, K., \& Schwartz, S. (1992). Explaining choices in procedural and distributive justice across cultures. International Journal of Psychology, 27, 211-225.

[4] Braun, D.E., Prusaczyk, W.K., Goforth, H.W. Jr., \& Pratt, N.C. (1994). Personality profiles of U.S. Navy Sea-Air-Land (SEAL) personnel. Technical Report, Naval Medical Research and Development Command, Department of the U.S. Navy.

[5] Burbeck, E., \& Furnham, A. (1984). Police officer selection: Trait differences in successful and non-successful applicants to the metropolitan police. Personality and Individual Differences, 5, 257-263.

[6] Carlson, L.D., \& Lester, D. (1980). Thrill seeking in police officers. Psychological Reports, 47, 1102.

[7] Carver, C.S., \& Connor-Smith, J. (2010). Personality and Coping. Journal of Annual Review of Psychology, 61, 679 704.

[8] Fang-juan Liao. (1999). Death attitudes among Taiwan police (unpublished manuscript).

[9] Folkman, S., \& Lazarus, R. S. (1988). Manual for the ways of coping questionnaire. Palo Alto, CA: Consulting Psychologists Press.

[10] Garbarino, S., Chiorri, C., Magnavita, N., Piattino, S. \& Cuomo, G. (2012). Personality Profiles of Special Force Police Officers Journal of Police and Criminal Psychology, 27, 99-110.

[11] Goma-i-Freixanet, M., \& Wismeijer, A.A.J. (2002). Applying personality theory to a group of police bodyguards: A physically risky prosocial prototype? Psicothema, 14, 387-392. 
[12] Griffeth, R., \& Cafferty, T. (1977). Police and citizen value systems: some cross-sectional comparisons. Journal of Applied Social Psychology, 7, 191-204.

[13] Griffith, J., \& Hart, L. (2005). Collegiate Skydivers: Do They Fear Death? Journal of Worry and Affective Experience, 1 (2), 71-76.

[14] Hartmann, E., Sunde, T., Kristensen, W., \& Martinussen, M. (2003). Psychological measures as predictors of training performance. Journal of Personality Assessment, 80, 87-98.

[15] Homant, J. R., Kennedy, D. B., \& Howton, J. D. (1993). Sensation seeking as a factor in police pursuit. Criminal Justice and Behavior, 20 (3), 293-305.

[16] Hopper, M. (1977). Becoming a policeman: Socialization of cadets in a police academy. Urban Life, 6, 149-168.

[17] Jack, S. J., \& Ronan, K. R. (1998). Sensation seeking among high- and low-risk sports participants. Personality and Individual Differences, 25, 1063-1083.

[18] Kaspar, F. E., \& Vesper, J. J. (1976). Death anxiety in risk-taker group. Essence, 1, 95 -97.

[19] Kobasa, S. C. (1979). Personality and resistance to illness. American Journal of Community Psychology, 7(4), 413-423.

[20] Koniarek, J., Dudek, B., \& Makowska, Z. (1993). The Sense of Coherence Questionnaire (SOC). Adaptation," Przeglad Psychologiczny, 36(4), 491 - 502.

[21] Lazarus R. S., \& Folkman S. (1984). Stress, appraisal and coping. New York: Guilford Press. Lester, D. (1983). Why do people become police officers: A study of reasons and their predictions of success. Journal of Police Science and Administration, 11, 170-174.

[22] Levin, B. H., \& Brown, W. E. (1975). Susceptibility to boredom of jailers and law enforcement Officers, Psychological Reports, 36(1), 190.

[23] Llewellyn, D. J., \& Sanchez, X. (2008). Individual differences and risk taking in rock climbing. Psychology of Sport and Exercise, 9, 413-426.

[24] McDonald, D.G., Norton, J.P., \& Hodgdon, J.A. (1990). Training success in U.S. Navy special forces. Aviation Space. Environmental Medicine, 61, 548-554.

[25] Meagher, S., \& Yentes, N. (1986). Choosing a career in policing: A comparison of male and female perceptions. Journal of Police Science and Administration, 14, 320-327.

[26] Oleś, P. (1995). Kryzys polowy życia u mężczyzn (Crisis of midlife among men). Lublin: RW KUL

[27] Paton, D., \& Violanti, J.M. (ed.). (1996). Traumatic stress in critical occupations: Recognition, consequences and treatment. Illinois, USA: Thomas Books.

[28] Picano, J.J., Roland, R.R., Rollins, K.D., \& Williams, T.J. (2002). Development and validation of a sentence completion test measure of defensive responding in military personnel assessed for nonroutine missions. Military Psychology,14, 279-298.
[29] Próchniak, P. (2009a). Preferowane wartości policjantów z jednostek specjalnych KFOR.(Preferred values of the policemen from special units KFOR), Roczniki Psychologiczne (Annals of Psychology) 12 (2), 41-53.

[30] Próchniak, P. (2009b). Polish police officers: Risk taking and Personality. Journal of Police and Criminal Psychology, 24(2), 104-110.

[31] Próchniak, P. (2011). Psychological profile of Polish skydivers. Psychological Reports, 108, 1-11.

[32] Próchniak, P. (2012). Personality traits and preferred values of fearless and courageous policemen. International Journal of Psychological Studies, 4 (4), 113-120.

[33] Próchniak, P. (2014). Firefighters: Prosocial risk taking and time orientation. Journal of Social Behavior and Personality 42 (2), 253-259.

[34] Raganella, A., J. \& White, M., D. (2004). Race, gender, and motivation for becoming a police officer: Implications for building a representative police department. Journal of Criminal Justice, 32 (6), 501-513.

[35] Roccas, S., Sagiv, L., Schwartz, S. H., \& Knafo, A. (2002). The big five personality factors and personal values. Personality and Social Psychology Bulletin, 6, 789-801.

[36] Schwartz, S. H. (1992). Universals in the content and structure of values: Theoretical advances and empirical tests in 20 countries. In: M. P. Zanna (ed.), Advances in experimental social psychology, Vol. 25 (pp. 1-65). New York: Academic Press.

[37] Schwartz, S. H., Sagiv, L., \& Boehenke, K. (2000). Worries and values. Journal of Personality, 68(2), 309-346.

[38] Tarng, M., Hsieh, C., \& Deng, T. (2001). Personal background and reasons for choosing a career in policing: An empirical study of police students in Taiwan. Journal of Criminal Justice, 29, 45-56.

[39] Violanti, J.M., \& Aron, F. (1993). Sources of police stressors, job attitudes and psychological distress. Psychological Reports, 72, 899-904.

[40] Zimbardo, Ph. G., Keough, K. A., \& Boyd, J. N. (1997). Present time perspective as a predictor of risky driving. Personality and Individual Differences, 23 (6), 1007-1023.

[41] Zimbardo, Ph. G., \& Boyd, J. N. (1999) Putting time in perspective: a valid reliable individual differences metric. Journal of Personality and Social Psychology, 77, 1271-1288.

[42] Zuckerman, M. (1992). What is a basic factor and which factors are basic? Turtles all the way down. Personality and Individual Differences, 13, 675-682.

[43] Zuckerman, M. (1994). Behavioral expressions and biosocial bases of sensation seeking. New York, Cambridge: University Press.

[44] Zuckerman, M., Kuhlman, D. M., Joireman, J., Teta, P., \& Kraft, M. (1993). A comparison of three structural models for personality: The big three, the big five, and the alternative five. Journal of Personality and Social Psychology, 65(4), 757-768. 